\title{
Recall of past activity levels in young adults is predictive of adolescent activity levels
}

\author{
Kristi L. Storti ${ }^{1^{*}}$, Emily R. Lawrentz ${ }^{1}$, Vincent C. Arena ${ }^{2}$, Robert J. Robertson ${ }^{3}$, \\ Elizabeth F. Nagle ${ }^{3}$, Andrea M. Kriska ${ }^{1}$ \\ ${ }^{1}$ Department of Epidemiology, University of Pittsburgh, Graduate School of Public Health, Pittsburgh, USA; \\ *Corresponding Author: stortik@edc.pitt.edu \\ ${ }^{2}$ Department of Biostatistics, University of Pittsburgh, Graduate School of Public Health, Pittsburgh, USA \\ ${ }^{3}$ Department of Physical Activity and Health, University of Pittsburgh, Pittsburgh, USA
}

Received 6 March 2013; revised 26 April 2013; accepted 13 May 2013

Copyright (C) 2013 Kristi L. Storti et al. This is an open access article distributed under the Creative Commons Attribution License, which permits unrestricted use, distribution, and reproduction in any medium, provided the original work is properly cited.

\section{ABSTRACT}

Purpose: To determine whether a global physical activity question (GPAq) administered in young adulthood can be used to accurately rank former physical activity levels (PA) relative to peers of the same age and sex during adolescence. Methods: Data were obtained from the Physical Activity in Young Adults Study, a 10year follow-up study of 12 - 16 year old adolescents. Five hundred twenty-eight young adults, mean age $24.5( \pm 1.0)$ years, completed a GPAq regarding current and past (adolescent) PA. GPAq answers were used to determine whether young adults could accurately rank their past (adolescent) PA levels relative to peers of the same age and sex. GPAq responses were compared with actual self-reported PA levels assessed by the Modifiable Activity Questionnaire for Adolescents (MAQ-A; collected during adolescence). For adolescent PA, an average of 4 years of activity from the MAQ-A 1990-1993, was used. Results: Regardless of gender, Jonckheere-Terpstra tests for trend $(p<0.0001)$ suggest significant linear trends across categories of PA level for the MAQ-A. Higher perceived PA tracked with greater past PA activity and lower perceived PA tracked with lower past PA activity. Conclusions: Young adults who classified themselves as more active as an adolescent were found to be relatively more active based upon self-reported activity from recall questionnaires collected during that time. These findings suggest that young adults can reasonably estimate relative PA levels during their adolescent years with GPAq. Global physical activity questions may be valid for the assessment and classification of previous PA levels.

Keywords: Recall; Adolescent; Self-Report; Modifiable Activity Questionnaire for Adolescents

\section{INTRODUCTION}

Self-report questionnaires are the most frequently used method to measure physical activity among free-living populations due to the ability to capture data on large numbers of individuals with limited cost. Self-report methods vary in their complexity, from global single-item questionnaires that may ask the respondent to rate their relative physical activity compared to others their same age and sex, to more complex quantitative history questionnaires estimating physical activity over a lifetime. Global activity questionnaires are typically short surveys that can be self-administered $[1,2]$ to obtain a general index of physical activity status or classification. This information can then be used to crudely rank individuals in a population from least to most active [1,2]. Rankings such as this may be valuable when examining disease outcomes in individuals or groups and may be used to adjust for the effect of physical activity when examining specific associations [3]. When examining current health status, information regarding past physical activity levels may be important, but not always available. Global activity questions about historical activity levels, if proven to be accurate, may be useful in providing crude rankings of an individual's physical activity levels from previous time periods. Being able to use a proxy measure may enhance the ability of future research to study the association between past physical activity levels and lifestyle-related diseases; and may be a cost effective alternative to collecting data over a long time period. 
The current study investigated whether young adults can accurately classify their former physical activity levels in adolescence using a global close-ended activity question (GPAq). The responses to this global question inquiring about adolescent physical activity relative to peers of the same age and sex were validated by comparing responses obtained in adulthood to actual selfreport physical activity data collected during adolescence (1990-1993). If shown to be valid, the GPAq can be used in studies of adults when the crude ranking of adolescent physical activity data is needed but not available.

\section{METHODS}

\subsection{Study Population}

Study participants for this investigation come from the Epidemiology of Physical Activity from Adolescence to Adulthood study, a 20-year longitudinal cohort that has been followed from adolescence to adulthood. The original participants, 12 - 16 years old at baseline $[n=1245$ adolescents ( $89 \%$ of the total student population)] were recruited in 1989 when they were enrolled in junior high school at a single school district in Pittsburgh, PA and followed for a period of four years (Phase I). The cohort consisted of similar numbers of male $(n=641)$ and female $(n=604)$ adolescents; and the racial composition was 73\% white, 24\% African American, and 3\% Hispanic or Asian [4-6]. In 1999, participants were recontacted (aged 22 - 25 years of age) to participate in a follow-up study to examine changes in physical activity from adolescence to young adulthood (Phase II). A total of $827(66 \%)$ completed an interviewer-administered, follow-up questionnaire which included information about health behaviors (i.e., smoking, drug and alcohol use, sedentary behavior), physical activity, and a global closeended activity question regarding physical activity perception in adolescence. Each phase of the current study was approved by the University of Pittsburgh Institutional Review Board and written informed consent was obtained from all participants and/or their parents prior to participation in any part of the study.

\subsection{Adolescent Physical Activity Measures}

During Phase I (1990-1993), physical activity was assessed using the Modifiable Activity Questionnaire for Adolescents (MAQ-A) [7]. The MAQ-A is an interviewer-administered, adolescent-specific questionnaire based on the Modifiable Activity Questionnaire (MAQ) for adults which assesses past-year participation in leisure time and competitive activities. The MAQ-A has been shown to provide reproducible and valid estimates of past year physical activity in adolescents [4,8]. During adolescence (Phase I), participants completed the MAQA during the spring of each year under the supervision of trained research assistants. Students were asked to report the frequency and duration of all activities that they participated in at least 10 times over the past year. The MAQ-A questionnaire included a list of 26 common physical activities, and the students could add recreational or non-occupational activities that were not included in the given list. The estimated number of hours spent on average for each activity per day was calculated. The average hours per day of all activities was summed to give an estimate of the total physical activity in hours per week over the past year.

During the 1999/2000 follow-up (Phase II) participants, now young adults, completed a physical activity and health habits questionnaire which included a global close-ended activity question inquiring about perception of adolescent physical activity levels. Using this global close-ended activity question, participants were asked to classify their adolescent physical activity levels relative to their peers during adolescence (1990-1993). Specifically, participants were asked: "When you were an adolescent (age 13 - 18) how active were you compared to others of your same age and sex, would you say that you were: much less active, somewhat less active, about as active, somewhat more active, or much more active?"

\subsection{Statistical Methods}

Only participants that had adolescent physical activity data (Phase I) available at all time-points, years 1990, 1991, 1992, 1993 and completed the global close-ended physical activity question in adulthood (Phase II) were included in the analysis. Descriptive statistics of the young adult cohort were calculated for the total cohort and by gender. All continuous data were assessed for normality. Normally distributed data are reported as mean (standard deviation) and non-normal variables as median (interquartile range). Categorical data are presented as percentages. Physical activity data was found to be skewed and were transformed prior to analysis using the square root of hours of physical activity.

Using the global physical activity question answered in adulthood, participants were categorized according to their response as much less active, somewhat less active, about as active, somewhat more active, or much more active. Additionally, the physical activity data from the MAQ-A completed in adolescence was categorized into quintiles of activity that were gender-specific. The Jonckheere-Terpstra test for trend $[9,10]$ was then used to determine if the physical activity quintiles were ordered in the same direction as the global physical activity question classifications, thus indicating a trend (i.e., do a greater proportion of individuals in the highest perceived PA categories track with a greater proportion of individuals falling in the higher past PA activity quintiles, 
and do a greater proportion of individuals falling in the lower perceived PA categories track with a greater proportion of individuals falling in the lower past PA quintiles. Statistical analyses were performed using Statistical Analysis Software, version 9.2 (SAS Institute Inc., Cary, North Carolina). Statistical significance was considered as a $\mathrm{p}$ value $<0.05$.

\section{RESULTS}

\subsection{Baseline Descriptives}

A total of 548 participants (273 males and 275 females) had complete data from the physical activity measures at Phase I and completed the global close-ended physical activity question in adulthood (Phase II). Descriptive statistics of the 1999 follow-up young adult cohort are presented in Table 1. The mean age of the cohort was 24.5 $( \pm 1.0)$ years. Overall, the sample was predominately white and unmarried with approximately $74 \%$ reporting working full time and $43 \%$ reporting a bachelor's degree or higher.

\subsection{Physical Activity Classification}

Table 2 presents gender-specific cross-classification of physical activity reported in adolescence (MAQ-A) as quintiles by GPAq assessed in young adulthood. Jonckheere-Terpstra test for trend, conducted separately for each gender, indicated that there was a significant increase in reported physical activity levels (based on the MAQ-A) across the increasing levels of physical activity classification (based on GPAq) $(p<0.0001)$. Examining the tables we notice that there is the tendency to be in the lower two quintiles of physical activity as an adolescent (MAQ-A) when individuals reported being much less or somewhat less active in contrast to those who were about, somewhat more, or much more active. Furthermore we note that among those who report being somewhat more, or much more active tended to be in the higher quintiles. This is observed for males and females, although more consistent in the latter which is attributed to the small number of males $(\mathrm{n}=10)$ falling in the much less active category. When the two lowest groups were collapsed the relationship is more noticeable. These results indicate a significant linear trend in physical activity levels, as assessed by the MAQ-A, across each physical activity classification from the GPAq for both males and female. We conducted additional analyses, taking educational and employment status into consideration, and noted similar significant findings for the total cohort and by gender (data not shown).

\section{CONCLUSIONS}

The current study investigated whether young adults
Table 1. Descriptive characteristics of the epidemiology of physical activity from adolescence to adulthood study population for the total cohort and stratified by gender at follow-up, 1999.

\begin{tabular}{|c|c|c|c|}
\hline Characteristic & $\begin{array}{c}\text { Total } \\
(\mathrm{n}=548)\end{array}$ & $\begin{array}{c}\text { Females } \\
(\mathbf{n}=275)\end{array}$ & $\begin{array}{c}\text { Males } \\
(\mathbf{n}=273)\end{array}$ \\
\hline Age & $24.5(1.0)$ & $24.4(1.1)$ & $24.6(0.9)$ \\
\hline Weight (pounds) & $166.8(39.5)$ & $146.6(34.2)^{*}$ & $186.1(34.1)$ \\
\hline $\begin{array}{l}\text { Body Mass Index } \\
\left(\mathrm{kg} / \mathrm{m}^{2}\right)\end{array}$ & $25.4(4.6)$ & $24.5(5.1)^{*}$ & $26.3(4.0)$ \\
\hline \multicolumn{4}{|l|}{ Race (\%) } \\
\hline White & 86.0 & 84.4 & 87.6 \\
\hline Non-white & 14.0 & 15.6 & 12.4 \\
\hline \multicolumn{4}{|l|}{$\begin{array}{l}\text { Relationship Status } \\
\text { (\%) }\end{array}$} \\
\hline Never Married & 63.8 & 57.3 & 70.3 \\
\hline $\begin{array}{l}\text { Living with } \\
\text { Unmarried Partner }\end{array}$ & 16.5 & 17.9 & 15.0 \\
\hline Married & 17.6 & 22.6 & 12.5 \\
\hline Separated & 0.9 & 0.7 & 1.1 \\
\hline Divorced & 1.3 & 1.5 & 1.1 \\
\hline Children (\%) & 21.8 & 27.0 & 16.5 \\
\hline \multicolumn{4}{|l|}{ Education (\%) } \\
\hline$<$ High School & 2.2 & 2.2 & 2.2 \\
\hline High School/GED & 35.6 & 28.4 & 42.9 \\
\hline Trade School & 4.7 & 4.4 & 5.1 \\
\hline Associates Degree & 14.8 & 18.2 & 11.4 \\
\hline Bachelors Degree & 38.2 & 41.1 & 35.2 \\
\hline$>$ Bachelors Degree & 4.6 & 5.8 & 3.3 \\
\hline \multicolumn{4}{|l|}{ Employment (\%) } \\
\hline Working Full Time & 73.7 & 69.8 & 77.7 \\
\hline Working Part Time & 8.6 & 11.6 & 5.5 \\
\hline Active Military & 1.6 & 0.4 & 2.9 \\
\hline Unemployed & 4.4 & 5.5 & 3.3 \\
\hline Disabled & 0.9 & 0.0 & 0.4 \\
\hline $\begin{array}{l}\text { Full Time } \\
\text { Homemaker }\end{array}$ & 2.2 & 4.0 & 0.4 \\
\hline Full Time Student & 8.6 & 8.7 & 8.4 \\
\hline \multicolumn{4}{|l|}{$\begin{array}{l}\text { Physical Activity, } \\
\text { hrs/wk }\end{array}$} \\
\hline Adult & $6.3(1.7)$ & $4.4(1.2)$ & $8.4(2.0)$ \\
\hline Adolescence & $13.7(2.0)$ & $9.0(1.2)$ & $19.4(1.4)$ \\
\hline
\end{tabular}

All data are presented as Mean (Standard Deviation) unless otherwise noted. ${ }^{*} 5 \%$ of women did not report weight, BMI could not be calculated. ${ }^{\dagger}$ Physical activity values reported for adolescence are based upon the Modifiable Activity Questionnaire for Adolescents and are mean values from years 19901993 during adolescence.

can accurately classify their former physical activity levels in adolescence using a global close-ended activity question (GPAq). It was found that young adults who perceived themselves as less active than their peers during adolescence were actually less active based on responses to the MAQ-A years prior. Likewise, those who perceived themselves as more active than their peers were relatively more active based upon the MAQ-A. 
Table 2. Gender-specific cross-classification of physical activity reported in adolescence by Modifiable Activity Questionnaire for Adolescence (MAQ-A) as quintiles by Global Activity Question (GPAq) assessed in young adulthood*.

\begin{tabular}{|c|c|c|c|c|c|c|c|c|c|c|c|c|}
\hline \multirow{7}{*}{ 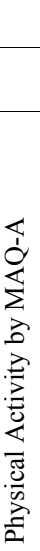 } & & \multicolumn{11}{|c|}{ Global Activity Question Responses } \\
\hline & & \multicolumn{5}{|c|}{$\begin{array}{c}\text { Males } \\
\mathrm{n}=273\end{array}$} & \multicolumn{6}{|c|}{$\begin{array}{l}\text { Females } \\
\mathrm{n}=275\end{array}$} \\
\hline & & $\begin{array}{l}\text { Much Less } \\
\text { Active }\end{array}$ & $\begin{array}{l}\text { Somewhat } \\
\text { Less } \\
\text { Active }\end{array}$ & $\begin{array}{l}\text { About as } \\
\text { Active }\end{array}$ & $\begin{array}{l}\text { Somewhat } \\
\text { More } \\
\text { Active }\end{array}$ & $\begin{array}{l}\text { Much } \\
\text { More } \\
\text { Active }\end{array}$ & $\begin{array}{l}\text { Much Less } \\
\text { Active }\end{array}$ & $\begin{array}{c}\text { Somewhat } \\
\text { Less } \\
\text { Active }\end{array}$ & $\begin{array}{l}\text { About as } \\
\text { Active }\end{array}$ & $\begin{array}{l}\text { Somewhat } \\
\text { More } \\
\text { Active }\end{array}$ & $\begin{array}{l}\text { Much } \\
\text { More } \\
\text { Active }\end{array}$ & \\
\hline & $\begin{array}{c}<11.3 \\
\text { hours/week }\end{array}$ & $\begin{array}{c}40.0 \% \\
\mathrm{n}=4\end{array}$ & $\begin{array}{c}33.3 \% \\
\mathrm{n}=6\end{array}$ & $\begin{array}{l}23.7 \% \\
n=23\end{array}$ & $\begin{array}{l}19.4 \% \\
\mathrm{n}=13\end{array}$ & $\begin{array}{l}9.9 \% \\
\mathrm{n}=8\end{array}$ & $\begin{array}{c}30.0 \% \\
\mathrm{n}=3\end{array}$ & $\begin{array}{l}29.7 \% \\
\mathrm{n}=11\end{array}$ & $\begin{array}{l}23.6 \% \\
n=25\end{array}$ & $\begin{array}{c}12.9 \% \\
\mathrm{n}=9\end{array}$ & $\begin{array}{c}13.5 \% \\
\mathrm{n}=7\end{array}$ & $\begin{array}{c}<3.9 \\
\text { hours/week }\end{array}$ \\
\hline & $\begin{array}{c}<17.6 \\
\text { hours/week }\end{array}$ & $\begin{array}{c}10.0 \% \\
\mathrm{n}=1\end{array}$ & $\begin{array}{c}33.3 \% \\
\mathrm{n}=6\end{array}$ & $\begin{array}{l}19.6 \% \\
n=19\end{array}$ & $\begin{array}{l}23.9 \% \\
\mathrm{n}=16\end{array}$ & $\begin{array}{l}16.0 \% \\
\mathrm{n}=13\end{array}$ & $\begin{array}{c}50.0 \% \\
\mathrm{n}=5\end{array}$ & $\begin{array}{c}24.3 \% \\
\mathrm{n}=9\end{array}$ & $\begin{array}{l}21.7 \% \\
\mathrm{n}=23\end{array}$ & $\begin{array}{l}17.1 \% \\
\mathrm{n}=12\end{array}$ & $\begin{array}{c}11.5 \% \\
\mathrm{n}=6\end{array}$ & $\begin{array}{c}\quad<7.1 \\
\text { hours/week }\end{array}$ \\
\hline & $\begin{array}{c}<22.6 \\
\text { hours/week }\end{array}$ & $\begin{array}{c}10.0 \% \\
\mathrm{n}=1\end{array}$ & $\begin{array}{c}22.2 \% \\
\mathrm{n}=4\end{array}$ & $\begin{array}{l}22.7 \% \\
n=22\end{array}$ & $\begin{array}{l}17.9 \% \\
n=12\end{array}$ & $\begin{array}{l}19.8 \% \\
\mathrm{n}=16\end{array}$ & $\begin{array}{c}20.0 \% \\
\mathrm{n}=2\end{array}$ & $\begin{array}{l}32.4 \% \\
n=12\end{array}$ & $\begin{array}{l}17.0 \% \\
\mathrm{n}=18\end{array}$ & $\begin{array}{l}22.9 \% \\
\mathrm{n}=16\end{array}$ & $\begin{array}{c}13.5 \% \\
\mathrm{n}=7\end{array}$ & $\begin{array}{c}<9.5 \\
\text { hours/week }\end{array}$ \\
\hline & $\begin{array}{c}<29.8 \\
\text { hours/week }\end{array}$ & $\begin{array}{c}30.0 \% \\
\mathrm{n}=3\end{array}$ & $\begin{array}{l}5.6 \% \\
n=1\end{array}$ & $\begin{array}{l}16.5 \% \\
n=16\end{array}$ & $\begin{array}{l}22.4 \% \\
\mathrm{n}=15\end{array}$ & $\begin{array}{l}24.7 \% \\
\mathrm{n}=20\end{array}$ & $\begin{array}{l}0.0 \% \\
\mathrm{n}=0\end{array}$ & $\begin{array}{l}8.1 \% \\
\mathrm{n}=3\end{array}$ & $\begin{array}{l}23.6 \% \\
\mathrm{n}=25\end{array}$ & $\begin{array}{l}20.0 \% \\
\mathrm{n}=14\end{array}$ & $\begin{array}{l}25.0 \% \\
\mathrm{n}=13\end{array}$ & $\begin{array}{c}<15.4 \\
\text { hours/week }\end{array}$ \\
\hline & $\begin{array}{c}\geq 29.8 \\
\text { hours/week }\end{array}$ & $\begin{array}{c}10.0 \% \\
\mathrm{n}=1\end{array}$ & $\begin{array}{l}5.6 \% \\
\mathrm{n}=1\end{array}$ & $\begin{array}{l}17.5 \% \\
n=17\end{array}$ & $\begin{array}{l}16.4 \% \\
n=11\end{array}$ & $\begin{array}{l}29.6 \% \\
n=24\end{array}$ & $\begin{array}{l}0.0 \% \\
\mathrm{n}=0\end{array}$ & $\begin{array}{l}5.4 \% \\
\mathrm{n}=2\end{array}$ & $\begin{array}{l}14.2 \% \\
\mathrm{n}=15\end{array}$ & $\begin{array}{l}27.1 \% \\
n=19\end{array}$ & $\begin{array}{l}36.5 \% \\
n=19\end{array}$ & $\begin{array}{c}\geq 15.4 \\
\text { hours/week }\end{array}$ \\
\hline & Total & $\begin{array}{c}100.0 \% \\
\mathrm{n}=10\end{array}$ & $\begin{array}{c}100.0 \% \\
\mathrm{n}=18\end{array}$ & $\begin{array}{c}100.0 \% \\
\mathrm{n}=97\end{array}$ & $\begin{array}{c}100.0 \% \\
\mathrm{n}=67\end{array}$ & $\begin{array}{c}100.0 \% \\
\mathrm{n}=81\end{array}$ & $\begin{array}{c}100.0 \% \\
\mathrm{n}=10\end{array}$ & $\begin{array}{c}100.0 \% \\
\mathrm{n}=37\end{array}$ & $\begin{array}{l}100.0 \% \\
n=106\end{array}$ & $\begin{array}{c}100.0 \% \\
\mathrm{n}=70\end{array}$ & $\begin{array}{c}100.0 \% \\
\mathrm{n}=52\end{array}$ & Total \\
\hline
\end{tabular}

Data is presented as column percent and frequency; ${ }^{*}$ Jonckheere-Terpstra Test for Trend $\mathrm{p}<0.0001$ for both males and females.

Similar to previous studies, the present findings suggest that global activity questions, asking participants to self-rate physical activity relative to peers may be valid for the assessment of physical activity levels [11-15]. For example, one such study [14] compared three single-item self-assessment questions regarding physical activity to energy expenditure based on answers to a more detailed series of questions from the National Health Interview Survey. Results from this study indicated that single-item questions were able to estimate leisure physical activity in a population. Similarly, an alternate study [11] found that a single item physical activity question was moderately correlated with time spent in physical activity assessed by extensive interview. Lastly, a study [12] used body mass index, HDL cholesterol, and oxygen capacity to validate a single question asking participants if they currently participate in any regular activity designed to improve or maintain physical fitness. This study found that the single global question was significantly associated with body mass index and oxygen capacity in both sexes and with HDL cholesterol in women. However, all of these previous studies examined global activity questions and their relationship to more detailed measures of activity levels administered during the same time frame and not longitudinally. The current study differs in that it compares answers to a global activity question administered in adulthood, which classify physical activity levels relative to those of peers in adolescence, to measures of a more detailed physical activity interview that was administered during adolescence.

Our results, however, are similar to other published findings [16], indicating no decay in the accuracy of re- porting previous activity levels up to 10 years in the past. The Aerobics Center Longitudinal Study examined the construct validity of self-reported historical walking, running, and jogging activity during a 10-year recall period using cardiorespiratory fitness and previously measured health markers. For each year of the study, participants were asked to report whether they engaged in walking, running, or jogging and to approximate the frequency and time. Spearman and partial correlations, indicted significant associations between recalled activity (MET-hrs per week) and treadmill time for each year during the 10-year period (rho $=0.40-0.61)$. The strength of the relationship between treadmill time and self-reported historical activity did not appreciably diminish with a longer period of recall.

There are several strengths of the present investigation, most importantly, the longitudinal nature of the data collected on participants from adolescence to young adulthood. This study allows for the direct comparison of data collected during adolescence from 1990-1993 (MAQ-A) with questionnaire data from 1999 (global close-ended activity question). Finally, the study population is unique in that it includes individuals from a wide range of educational levels and employment status.

There are limitations that should be considered when interpreting the findings of the current study. First, the study population was fairly homogenous regarding race, with only $14 \%$ being non-white and only half of the original study population was included in the analyses. Also, the participants were all young adults $(24.5 \pm 1.0$ years), so time to recall was not as long as that of an older cohort, and may not be generalizable to older indi- 
viduals.

Information regarding past physical activity levels may be important when examining current health outcomes however this information may be not always available. In such cases, a proxy estimate of physical activity may be useful. The current study investigated whether young adults can accurately classify their former physical activity levels in adolescence using a global close-ended activity question. The results of the current study noted that participants were able to reasonably classify historical physical activity levels compared to their peers using a global activity question and were consistent for both male and female young adults. Being able to estimate relative historical physical activity level using proxy measures may enhance the ability of future research to study the association between past physical activity levels and lifestyle-related diseases and may be a cost effective alternative to collecting data over a long time period.

\section{ACKNOWLEDGEMENTS}

This study was supported by grant AR39541 from the National Institute of Arthritis and Musculoskeletal and Skin Diseases and grant HD35607 from the National Institute of Child Health and Human Development. This manuscript is dedicated to the memory of Deborah J. Aaron, PhD, PI of the Physical Activity in Young Adults Study.

\section{REFERENCES}

[1] Siscovick, D.S., Ekelund, L.G., Hyde, J.S., Johnson, J.L., Gordon, D.J. and LaRosa, J.C. (1988) Physical activity and coronary heart disease among asymptomatic hypercholesterolemic men (the Lipid Research Clinics Coronary Primary Prevention Trial). American Journal of Public Health, 78, 1428-1431. doi:10.2105/AJPH.78.11.1428

[2] Sternfeld, B., Cauley, J., Harlow, S., Liu, G. and Lee, M. (2000) Assessment of physical activity with a single global question in a large, multiethnic sample of midlife women. American Journal of Epidemiology, 152, 678687. doi:10.1093/aje/152.7.678

[3] Kriska, A.M. and Caspersen, C.J. (1997) Introduction to the collection of physical activity questionnaires. Medicine and Science in Sports and Exercise, 29, S5-S9. doi:10.1097/00005768-199706001-00003

[4] Aaron, D.J., Storti, K.L., Robertson, R.J., Kriska, A.M. and LaPorte, R.E. (2002) Longitudinal study of the number and choice of leisure time physical activities from mid to late adolescence: implications for school curricula and community recreation programs. Archives of Pediatric and Adolescent Medicine, 156, 1075-1080. doi:10.1001/archpedi.156.11.1075

[5] Anderson, R., Dearwater, S.R., Olsen, T., Aaron, D.J.,
Kriska, A.M. and LaPorte, R.E. (1994) The role of socioeconomic status and injury morbidity risk in adolescents. Archives of Pediatric and Adolescent Medicine, 148, 245-249.

doi:10.1001/archpedi.1994.02170030015003

[6] LaPorte, R.E., Dearwater, S.R., Chang, Y.F., Songer, T.J., Aaron, D.J., Anderson, R.L., et al. (1995) Efficiency and accuracy of disease monitoring systems: Application of capture-recapture methods to injury monitoring. American Journal of Epidemiology, 142, 1069-1077.

[7] Kriska, A.M. and Caspersen, C.J. (1997) A collection of physical activity questionnaires. Medicine and Science in Sports and Exercise, 29, S79-S82.

doi:10.1097/00005768-199706001-00003

[8] Aaron, D.J., Kriska, A.M., Dearwater, S.R., Cauley, J.A., Metz, K.F. and LaPorte, R.E. (1995) Reproducibility and validity of an epidemiologic questionnaire to assess past year physical activity in adolescents. American Journal of Epidemiology, 142, 191-201.

[9] Jonckheere, A.R. (1954) A distribution-free k-sample test against ordered alternatives. Biometrika, 41, 133-145.

[10] Terpstra, T.J. (1952) The asymptomatic normality and consistency of Kendall's test against trend, when ties are present in one ranking. Indagationes Mathematicae, 14, 327-333.

[11] Iwai, N., Hisamichi, S., Hayakawa, N., Inaba, Y., Nagaoka, T., Sugimori, H., et al. (2001) Validity and reliability of single-item questions about physical activity. Journal of Epidemiology, 11, 211-218. doi:10.2188/jea.11.211

[12] Schechtman, K.B., Barzilai, B., Rost, K. and Fisher Jr., E.B. (1991) Measuring physical activity with a single question. American Journal of Public Health, 81, 771773. doi:10.2105/AJPH.81.6.771

[13] Taylor-Piliae, R.E., Fair, J.M., Haskell, W.L., Varady, A.N., Iribarren, C., Hlatky, M.A., et al. (2010) Validation of the Stanford brief activity survey: Examining psychological factors and physical activity levels in older adults. Journal of Physical Activity and Health, 7, 87-94.

[14] Weiss, T.W., Slater, C.H., Green, L.W., Kennedy, V.C., Albright, D.L. and Wun, C.C. (1990) The validity of single-item, self-assessment questions as measures of adult physical activity. Journal of Clinical Epidemiology, 43, 1123-1129. doi:10.1016/0895-4356(90)90013-F

[15] Jackson, A.W., Morrow Jr., J.R., Bowles, H.R., FitzGerald, S.J. and Blair, S.N. (2007) Construct validity evidence for single-response items to estimate physical activity levels in large sample studies. Research Quarterly for Exercise and Sport, 78, 24-31. doi:10.1080/02701367.2007.10599400

[16] Bowles, H.R., FitzGerald, S.J., Morrow Jr., J.R., Jackson, A.W. and Blair, S.N. (2004) Construct validity of self-reported historical physical activity. American Journal of Epidemiology, 160, 279-286. doi:10.1093/aje/kwh209 